\title{
(2) OPEN ACCESS \\ Clinical practice and teaching of pharmaceutical care procedures for obstetric diseases
}

\author{
Xianli Wang, Yanyu Pang, Mengmeng Wang, Jin Jing, Jing Tang
}

Department of Pharmacy, The Obstetrics and Gynecology Hospital of Fudan University, Shanghai, China

\section{Correspondence to Mrs Jing Tang, Shanghai, China; angel_tj99@126.com}

Received 1 August 2019 Revised 11 February 2020 Accepted 17 February 2020

EAHP Statement 4: Clinical Pharmacy Services.
Check for updates

(C) European Association of Hospital Pharmacists 2020. Re-use permitted under CC BY-NC. No commercial re-use. Published by BMJ.

To cite: Wang X, Pang Y,
Wang M, et al.
Eur J Hosp Pharm Epub
ahead of print: [please
include Day Month Year].
doi:10.1136/
ejhpharm-2019-002053

\section{ABSTRACT}

Objectives Our goal was to explore the pharmaceutical service and teaching methods of obstetric clinical pharmacists to establish standardised pharmaceutical care procedures for obstetric diseases.

Methods According to the evidence-based medicine method, the "Standard of Pharmaceutical Care" was established to standardise the procedure and content of the pharmaceutical care procedure including preface, purpose, scope of application, responsibilities, procedures, references, and appendix, with seven parts in total. The object of the pharmaceutical care procedure was selected by the harmfulness of the disease and the drugs used. The clinical pharmacists in obstetrics formulated the pharmaceutical care procedure for each disease according to the standard and carried out clinical practice and teaching.

A retrospective study was conducted to investigate the impact of the pharmaceutical care procedure before and after its implementation on both clinical practice and training. Obstetric pharmaceutical consultation and adverse reaction were the key indicators for clinical practice.

The graduation assessment for students was strictly carried out in accordance with the regulations of the Chinese Hospital Association Pharmaceutical Affairs Professional Committee including communication and consultation capacity interview, case assessment, and training procedure assessment.

Results We established the standards for the pharmaceutical care procedures for three diseases: pregnancy with diabetes; pregnancy with thyroid disease; and pregnancy with hypertensive disorder. The clinical pharmacist conducted the pharmaceutical care procedure, participated in drug treatment management, and improved the recognition of the role of clinical pharmacists by the obstetric clinicians, often inviting the clinical pharmacists to participate in the consultations. The clinical pharmacists discovered and addressed any adverse reactions in a timely manner through patient drug education, subsequently reducing the underreporting of adverse reactions and improving the patient's medication compliance, which aimed to improve the medical quality of patients in our hospital. Second, the use of the pharmaceutical care procedure as a teaching tool helped to train students to grasp the key points of drug treatment and care of the disease and improve the students' scores in the graduation assessment $(P<0.05)$.

Conclusions As a pharmacy service and teaching method that can be promoted and implemented, the pharmaceutical care procedure is beneficial for clinical pharmacists to carry out in-depth pharmaceutical services and can also be used as a teaching tool for clinical pharmacist training.

\section{INTRODUCTION}

\section{Current state of pharmaceutical care in China}

Pharmaceutical care has become a hot topic in the field of hospital pharmacy in China in recent years, and it is a new working model of hospital pharmacy. ${ }^{1}$ Pharmaceutical care requires pharmacist services to be "patient-centred" to detect potential clinical or actual medication problems through custody, to assist in clinical prevention of potential medication problems, to resolve issues with inappropriate medications that have been prescribed, and to ultimately improve patient outcomes. ${ }^{2}$

Traditionally, the job of the Chinese hospital pharmacist is to ensure the supply and dispensing of drugs. With the reform of hospital pharmacy work in China, pharmacists who "focus on drug dispensing" gradually changed to the clinical pharmacists who "provide the services of clinical drug treatment", ${ }^{3}$ which requires pharmacists to provide pharmaceutical care for patients, such as pharmaceutical ward rounding, optimising drug treatment programmes, drug education, and adverse drug reaction reporting. However, the pharmacists who dispense medicines have insufficient experience in drug therapy and the level of pharmacy service is uneven in China.

Due to the late start and slow development of clinical pharmacy services and teaching in China, there is no standard pharmaceutical care procedure or standardised teaching protocol for clinical pharmacists. Differences in the background of a clinical pharmacist's professional, pharmaceutical service experience, and education will lead to differences in medication advice and medication education provided by medical care, potentially putting patients at risk. Therefore, there is an urgent need for the establishment of standard pharmaceutical care procedures to improve and standardise pharmaceutical services.

\section{The challenges brought by the family planning policy with Chinese characteristics to clinical pharmacists in obstetrics}

In 1979, the one-child policy was introduced by the Chinese government. The negative consequences of the one-child policy are becoming increasingly obvious, including accelerating population ageing, the skewed sex ratio, and the decline in the working-age population, which would threaten economic growth. By 2007, the Chinese government started to permit couples who were both only-children to have two children. In November, 2013, a policy allowing couples in which at least one of the marital partners was an only child to have two children was introduced. In October, 2015, China's one-child policy was replaced by a universal two-child policy. 
The new policy will allow almost all Chinese people to have their preferred number of children. ${ }^{4}$

With the adjustment of the family planning policy, the proportion of elderly mothers in China is increasing, and the chance of high-risk pregnancy, pregnancy complications, and comorbidities is significantly higher in this population. For example, the incidence of hypertensive disorder in pregnancy increases 3-fold, and the incidence of gestational diabetes increases by 5.5 -fold. ${ }^{5}$ As medication for pregnant women is also related to the health of the child, it is necessary for clinical pharmacists to play a role in determining which drugs to use and when. Fudan University Obstetrics and Gynaecology Hospital (hereinafter referred to as "our hospital") is a well-known domestic obstetrics and gynaecology specialised hospital. From 2011 to 2014, the number of perinatal outpatient visits in our hospital increased from 144923 to 183339 , and the number of obstetric births increased from 12636 to 16743.

Pregnant women are in urgent need of clinical pharmacists to provide them with quality pharmaceutical care. Thus, the purpose of this study is to establish the pharmaceutical care process for clinical pharmacists in obstetrics and to investigate the application of the pharmaceutical care process in clinical pharmaceutical care practice and teaching.

\section{METHODS}

\section{Standards for the establishment of pharmaceutical care procedures}

Combined with evidence-based medicine and clinical pathway methods, ${ }^{67}$ we established a standard pharmaceutical care procedure to regulate the formulation procedure and specify the main content of the pharmaceutical care procedure, including preface, purpose, scope of application, responsibilities, procedures, references, and appendix, with seven parts in total. The preface is used to introduce the background of the disease, including definitions, hazards, and epidemiology. The purpose is to introduce the significance of the development of this pharmaceutical care procedure. The scope of application includes both the applicable places and population, and the responsibility is to clarify the role of the clinical pharmacist in the pharmaceutical care procedure. The development of the programme is the core content of the pharmaceutical care procedure, and is described as follows.

\section{Determination of the care object}

Through medical examination and pharmacists' rounds, the goal is to understand the condition of hospitalised patients and determine the target of pharmaceutical care.

\section{Pharmaceutical consultation}

The patient's chief complaint, current medical history, and past history should be collected by directly communicating with the patient, focusing on the history of previous medication, history of drug and food allergies, history of adverse drug reactions, and treatment measures taken. The record form should be filled out completely.

\section{Pharmaceutical evaluation}

According to the results of the pharmaceutical consultation, combined with the doctor's diagnosis and treatment plan, the pharmacist should comprehensively assess the patient's condition, compliance, medication strategy, and treatment efficacy.
Patients should be assessed again if their condition or medication regimen changes during hospitalisation.

\section{Optimisation of drug treatment plan}

The pharmacist should refer to the results of the pharmaceutical evaluation and actively communicate with the clinician to help optimise the drug treatment plan.

\section{Develop and implement a pharmaceutical care plan}

The pharmacist should integrate the profile of the patient's disease and medication to develop an individualised care programme and record the care results.

\section{Determination of pharmaceutical care indicators}

In the course of care, the patient's treatment effect and adverse drug reactions are judged. When the drug treatment plan changes, the clinical pharmacist timely adjusts the contents of the pharmaceutical care programme, including the efficacy and adverse reaction care.

\section{Conduct medication guidance}

According to the patient's medication situation, the reasons for the treatment, the usage and dosage, the common adverse reactions and disposal measures, and the precautions for medication, the pharmacist should intervene in improper drug use behaviour, answer the drug-related consultation questions, and have the mission record signed by the patient or her family. The pharmacist should also teach the patients before discharging them from the hospital concerning the following topics including exercise, diet and medication, at least including drug use and preservation methods, post-discharge follow-up indicators, and follow-up plans.

For each part of the procedure, we designed a standard record form to facilitate the recording of patient treatment information and the pharmaceutical care procedures. The format can be adjusted according to different diseases and patient characteristics to improve applicability. The main sources of evidence are listed in the references, and the format is referred to as the "National Standards for Rules for Content, Form and Structure of Bibliographic References of the People's Republic of China" (GB/T7714-2005).

The treatment plan and care indicators involved in the pharmaceutical care procedure were derived from the guidelines issued by international authoritative associations or organisations, such as the WHO and the International Federation of Obstetrics and Gynaecology, and the guidelines for diagnosis and treatment must be approved by the National Health Committee and issued by national associations, such as the American Association of Obstetricians and Gynecologists, Canadian Association of Obstetricians and Gynecologists, and the Chinese Medical Association. The rest of the evidence that can be referenced includes textbooks and monographs published by the People's Health Publishing House, Peking University Medical Press, and China Union Medical University Press. In practice, it is necessary to consider the time since the last update, authoritativeness, and clinical practice. To determine the usage and dosage of the drug, refer to the domestic drug manual. In special cases, the adoption of the drug in addition to the instructions is based on the following: the determined usage and dosage of the drugs in the instructions of other countries or regions; the guidelines for diagnosis and treatment issued by international authoritative associations or organisations; and the guidelines for diagnosis and treatment 
approved by the National Health Committee issued by the national associations.

\section{Formulation of the pharmaceutical care procedure for obstetric diseases}

Determination of the object of formulation for the pharmaceutical care procedure

The incidence of pregnancy combined with medical diseases such as hypertension, diabetes, and thyroid disease is increasing ${ }^{8-11}$ and these medical complications may lead to miscarriage, premature delivery, fetal growth restriction, nervous system developmental disorders, and even fetal death, if not treated properly. The drugs used in these comorbidities, such as insulin and magnesium sulfate injection, are high-risk drugs. In the course of treatment, clinical pharmacists need to continuously pay attention to the patient's clinical efficacy and adverse reactions. So we focused on three pregnancy complications: diabetes, hypertensive disorder, and thyroid disease. Pregnant women diagnosed with these diseases will be the object of pharmaceutical care.

\section{The development of the obstetric disease pharmaceutical care procedure}

Three clinical pharmacists who were engaged in clinical pharmacy services in obstetrics established the pharmaceutical care procedure for three diseases in accordance with the standard. The procedure was determined according to the clinical treatment guidelines for each disease and combined with the actual situation present in our hospital. These three clinical pharmacists are also the executors of each pharmaceutical care procedure.

\section{Application of pharmaceutical care procedure in teaching}

After clinical pharmacy student enrollment in September 2017, we applied the pharmaceutical care procedure to the teaching of drug treatment management, and the students participated in the management of the drug treatment according to the pharmaceutical care procedure. We compared the graduation assessment scores of the 2017 students ( $n=6$, experimental group) with the scores of the 2016 students $(n=4$, control group). The assessments were strictly carried out in accordance with the regulations of the Chinese Hospital Association Pharmaceutical Affairs Professional Committee. The assessment was divided into three parts, communication and consultation capacity interview, case assessment, and training procedure assessment.

\section{Statistical analysis}

The retrospective study was conducted to investigate the clinical and teaching effects of the pharmaceutical care procedure before and after the pharmaceutical care procedure implementation. When comparing the profile of students in the control and experimental group, the age and years of experience were compared using the Wilcoxon rank-sum test, and the education and position
Table 2 Changes in the number of reports of consultation and adverse reactions in obstetrics before and after the implementation of pharmaceutical care procedure

\begin{tabular}{llll}
\hline Time & $\begin{array}{l}\text { Obstetric } \\
\text { pharmaceutical } \\
\text { consultation (cases) }\end{array}$ & $\begin{array}{l}\text { Adverse } \\
\text { reaction } \\
\text { (cases) }\end{array}$ & $\begin{array}{l}\text { Number of obstetric } \\
\text { discharge } \\
\text { (cases) }\end{array}$ \\
\hline 2015 & 9 & 86 & 18271 \\
2016 & 19 & 93 & 23623 \\
2017 & 37 & 103 & 20239 \\
\hline
\end{tabular}

were compared using the Fisher test. When comparing the assessment of the abilities of the students in the two groups, the $t$-test was used. P-values $\leq 0.05$ were considered statistically significant. All statistical analyses were carried out using Stata 15 software.

\section{RESULTS}

\section{Clinical practice of pharmaceutical care procedures} Organising clinical pharmacists to practice

The procedure is applied by the clinical pharmacist who plans the pharmaceutical care procedure. Based on the practice of pharmaceutical care, the procedure and related forms are revised and improved according to the PDCA (Plan, Do, Check, Action) management loop. Clinical pharmacists further improve the care procedure in combination with their clinical practice, examine the effects of the application, evaluate clinical efficacy, medication compliance, and satisfaction in real time with the pharmaceutical services, Finally, combined with the pharmacist's own experience and medical feedback, they timely summarise and adjust the procedure. After a 6-month probationary period (June 2016 to December 2016), 134 patients were monitored by clinical pharmacists, and 23 cases of drug-related problems were found (table 1). Inappropriate drug use, low patient compliance, adverse drug reactions, and other issues were promptly communicated with the physician, so as to ensure the proper drug use. These methods improved the patient's treatment and medication compliance and also were adopted by clinicians and nurses. ${ }^{12} 13$

\section{Promotion and use of the pharmaceutical care procedure}

After the trial period of 6 months in 2016, it was promoted and used in 2017. The clinical pharmacists practised through the pharmaceutical care procedure, participated in the management of drug treatment, improved the recognition of clinical pharmacists by obstetric clinicians, and increased the number of clinical pharmacists participating in the consultation. Also, through drug education for the patients, the adverse drug reactions were discovered in a timely manner and remedied, which reduced the underreporting of adverse reactions, thereby improving the patient's medication compliance, and increasing the number of adverse reactions reported in our hospital (table 2).

Table 1 Summary of the issues found in the pharmaceutical care procedure by the clinical pharmacists

\begin{tabular}{ll}
\hline Issues & Details \\
\hline Improper drug usage & $\begin{array}{l}\text { Time error of insulin aspart (one case of medication half an hour before meal); time error of sodium levothyroxine medication (two cases of } \\
\text { postprandial medication) }\end{array}$ \\
\hline Low compliance & $\begin{array}{l}\text { Poor blood sugar control caused by improper diet (four cases), exercise (two cases), and poor understanding of blood sugar care methods } \\
\text { (one case); refusal to take propylthiouracil (one case); self-withdrawal of levothyroxine sodium (one case) }\end{array}$ \\
\hline Adverse reactions & $\begin{array}{l}\text { Magnesium sulfate injection (one case of sweating and fever, one case of sweating and headache, one case of shortness of breath which is } \\
\text { new general adverse reaction); ritodrine hydrochloride injection(one case of chest distress and palpitation, one case of hypokalemia); insulin } \\
\text { injection (two cases of hypoglycemia, one case of local allergic reaction such as pruritus and swelling caused by suspected recombinant } \\
\text { human insulin of protamine zinc, one case of hypokalemia, one case of abdominal distention which new general adverse reactions of } \\
\text { protamine zinc recombinant human insulin or insulin dieter); propylthiouracil (one case of damage of liver function). }\end{array}$ \\
\hline
\end{tabular}


Table 3 Summary of the drug proportion and treatment quality of the hospital across a number of years

\begin{tabular}{llll}
\hline Time & Drug proportion & $\begin{array}{l}\text { Average length of } \\
\text { stay (days) }\end{array}$ & $\begin{array}{l}\text { Turnover rate of } \\
\text { beds }\end{array}$ \\
\hline 2015 & $21.43 \%$ & 4.92 & $72.55 \%$ \\
2016 & $20.26 \%$ & 4.55 & $81.38 \%$ \\
2017 & $17.05 \%$ & 4.25 & $88.18 \%$ \\
\hline
\end{tabular}

In addition to the pharmaceutical care procedure, the clinical pharmacists also played an important role in drug use through lectures on proper drug use, case discussions and consultations, prescription review and evaluation, and key drug monitoring. Together with the medical management measures in our hospital, it has played a supporting role in improving the bed turnover rate and reducing the proportion of drugs used and the average length of hospital stay (table 3 ). Drug proportion = totaldrug revenue/ total hospital revenue $\times 100 \%$. In China, the index is used to reflect the level of hospital drug costs and income structure. The average length of hospital stay $=$ totalbed days/discharge. In China, the index is used to reflect the efficiency of hospital services for inpatients. Bed turnover rate $=$ discharge number/average number of beds $\times 100 \%$. In China, the index is used to reflect average number of times each bed is turned over in a given period of time. ${ }^{14}$

\section{Application of pharmaceutical care procedure in teaching clinical pharmacy students}

We compared the graduation assessment scores of the 2017 students (experimental group) with the scores of the 2016 students (control group). The two groups of students had no statistically significant difference in basic conditions such as age, education, and working years (table 4). The assessments were strictly carried out in accordance with the regulations of the Chinese Hospital Association Pharmaceutical Affairs Professional Committee. The two groups of students showed no statistically significant difference in the scores for communication and consultation capacity interview and training procedure assessment, but there was a statistically significant difference in the results of the case assessment centred on the "Clinical Practice Skills" (table 5, P<0.05).

\section{DISCUSSION}

With the development of clinical pharmacy in recent years, reports on the practice of pharmaceutical care provided by clinical pharmacists have gradually increased. Based on the specific disease treated and the work experience of the clinical pharmacist, the key content of pharmaceutical care varies, such as focusing on the medication education of inhalersfor asthma patients. ${ }^{15}$ For patients taking multiple drugs, medication compliance, drug interactions, and adverse reactions should be emphasised. ${ }^{16-18}$ Since the pharmaceutical management committee of the China Hospital Association only set up the training of clinical pharmacists in obstetrics and gynaecology in 2015, the training of
Table 5 The assessment of the abilities of the students in the two groups

\begin{tabular}{llll}
\hline Group & $\begin{array}{l}\text { Communication and } \\
\text { consultation capacity during } \\
\text { interview (out of 100) }\end{array}$ & $\begin{array}{l}\text { Training } \\
\text { procedure (out } \\
\text { of 100) }\end{array}$ & $\begin{array}{l}\text { Case } \\
\text { assessment } \\
\text { (out of 100) }\end{array}$ \\
\hline $\begin{array}{l}\text { Control }(n=4) \\
91.5 \pm 2.1\end{array}$ & $93.5 \pm 1.3$ & $86.3 \pm 2.9$ \\
$\begin{array}{l}\text { Experiment } \\
(n=6)\end{array}$ & $92.7 \pm 2.3$ & $94 \pm 2.5$ & $91.5 \pm 2.7$ \\
\hline
\end{tabular}

The case assessment was significantly different between the two groups, $t$-test, $\mathrm{P}<0.05$.

clinical pharmacists in obstetrics and gynaecology started late, and the practice of pharmaceutical care in this area was rarely reported. With the introduction of the "two-child policy", the number of elderly pregnant women in China is increasing, which has led to an increase in the number of pregnant women with medical diseases, such as hypertension and gestational diabetes mellitus. Through clinical practice, the authors found that many pregnant women worry about the adverse effects of medication during pregnancy on the growth and development of the fetus. This worry resulted in poor compliance, such as in patients with gestational hypertension who need long-term oral antihypertensive drug therapy who stopped taking drugs at will and those with gestational diabetes who need insulin control, but refuse insulin. ${ }^{12}$ Therefore, in this population, we need to focus on medication education and pharmaceutical care. Through years of work, and combined with the reports of other scholars, the authors established a standardised obstetric disease pharmaceutical care procedure and applied it in clinical obstetric pharmaceutical care and taught these standards to new students.

The results show that the standardised pharmaceutical care procedure for obstetric diseases established by the authors is beneficial for clinical pharmacists to carry out in-depth pharmaceutical care. Through pharmaceutical consultation, clinical pharmacists understood the drug treatment of patients and educated patients on drug use, strengthened patients' awareness of drug treatment of their own diseases, and improved drug compliance. In addition, pharmaceutical care can help clinical pharmacists judge treatment effects and monitor related adverse drug reactions and play a role in optimising drug treatment programmes and handling adverse drug reactions. With improvement in the abilities of clinical pharmacists and the recognition of clinicians, the number of times that clinicians invite clinical pharmacists to participate in consultation and case discussion increases, making pharmacists an indispensable member of the treatment team of physicians, pharmacists, and nurses. Clinical pharmacists also play a role in reducing the proportion of drugs through lectures on rational drug use and management of key monitored drugs, such as antibacterial drugs and adjuvant drugs. Adjuvant drugs are specified as an adjunctive use for a certain disease in the drug label or clinical diagnosis and treatment guide such as Coenzyme Complex, Creatine Phosphate Sodium, and Alprostadil. The use of these drugs alone cannot achieve the purpose of treating the disease. ${ }^{19}$ Second, the application of pharmaceutical care procedures in teaching can help

Table 4 Profile of the students in the control and experimental group

\begin{tabular}{lllll}
\hline Group & $\begin{array}{l}\text { Age } \\
\text { (years old) }\end{array}$ & Education & Title & Position \\
\hline Control $(n=4)$ & $28.5 \pm 1.7$ & $\begin{array}{l}\text { Master of Science }(n=2) \\
\text { Bachelor of Science }(n=2)\end{array}$ & Pharmacist $(n=4)$ & Clinical pharmacist $(n=4)$ \\
Experiment $(n=6)$ & $29.3 \pm 3.1$ & $\begin{array}{l}\text { Master of Science }(n=5) \\
\text { Bachelor of Science }(n=1)\end{array}$ & Chief pharmacist $(n=1)$ pharmacist $(n=5)$ & $2.8 \pm 1.6$ \\
\hline
\end{tabular}

The age and years of experience were compared with the Wilcoxon rank-sum test, $\mathrm{P}>0.05$. The education and position was compared with the Fisher test, $\mathrm{P}>0.05$. 
students understand the main practical steps and key points of pharmaceutical care, so as to train students to grasp the key points of drug treatment and care of diseases, and improve their clinical abilities.

\section{Limitations of the study}

There are some limitations in our study. First, due to the limitation of the number of clinical pharmacists in the obstetrics department of our hospital, the main diseases for which we implemented the pharmaceutical care procedure were gestational diabetes mellitus, gestational thyroid disease, and gestational hypertension. With process optimisation and the increasing number of clinical pharmacists in obstetrics, pharmaceutical care can be extended to more diseases, and more patients can receive clinical pharmaceutical care. Second, it was carried out only in our hospital, and the sample size was very small. It needs reproduction on a larger scale to confirm its benefits and be able to extrapolate the results to all obstetrics and gynaecology hospitals in China.

\section{CONCLUSIONS}

The clinical pharmacist uses the pharmaceutical care procedure as a tool based on clinical practice, which helps to discover and resolve potential or actual drug problems, thereby improving the patient's therapeutic effects, while enabling clinical pharmacists to play an important role in proper drug use. The pharmacy department of our hospital is the primary site for clinical pharmacist training for obstetrics and gynaecology majors certified by the Chinese Hospital Association. To ensure the quality of training for

\section{What this paper adds}

What is already known on this subject

- Due to the late start and slow development of clinical pharmacy services and teaching in China, there is no standard pharmaceutical care procedure or standardised teaching protocol for clinical pharmacists.

- The number of reports regarding the practices of pharmaceutical care provided by clinical pharmacists have gradually increased, particularly in regards to asthma patients, or patients who are taking multiple drugs.

- Traditionally, the job of the Chinese hospital pharmacist is to ensure the supply and dispensing of drugs. Therefore, most pharmacists have insufficient experience in the clinical administration and management of medications.

\section{What this study adds}

- This study establishes guidelines for practice and education, which are desperately required.

- The goal of our study was to devise and evaluate the effectiveness of our pharmaceutical care procedure to augment training and improve patient outcomes, particularly medication compliance and health outcomes. Specifically, our work focused on the management of complications during pregnancy, especially in older mothers. Increasing age during pregnancy has become common in China, with the implementation of the "two-child" policy.

- We used the pharmaceutical care procedure, which aimed to improve drug compliance, ensure proper drug use, and reduce adverse reactions, while training incoming pharmacy students in the course of delivering care. We saw a marked improvement in case results for students completing our new training programme. the students, we are committed to creating a scientific model of teaching in obstetrics and gynaecology for clinical pharmacists.

Correction notice This paper has been amended since it was published onine. There was a typographical error in the legend of table 3 which has been corrected.

Contributors XW, YP, MW, and JJ performed the study. XW analysed the data and wrote the paper. JT provided guidance for this study, critically revised the paper, and approved the final version to be published.

Funding This work was supported by The Key Specialty Construction Project of Shanghai Clinical Pharmacy (No. AB83110002017005) and Shanghai "Rising Stars of Medical Talent" Youth Development Program (No. AB83030002019004).

Competing interests None declared.

Patient consent for publication Not required.

Provenance and peer review Not commissioned; externally peer reviewed.

Data availability statement All data relevant to the study are included in the article or uploaded as supplementary information. None.

Open access This is an open access article distributed in accordance with the Creative Commons Attribution Non Commercial (CC BY-NC 4.0) license, which permits others to distribute, remix, adapt, build upon this work non-commercially, and license their derivative works on different terms, provided the original work is properly cited, an indication of whether changes were made, and the use is noncommercial. See: http://creativecommons.org/licenses/by-nc/4.0/.

\section{REFERENCES}

1 Luo LF, Dai HB. Literature analysis on pharmaceutical care in China. Chin Hosp Pharm J 2017;37:319-21.

2 Hepler CD, Strand LM. Opportunities and responsibilities in pharmaceutical care. Am J Hosp Pharm 1990;47:533-43.

3 YPW, Yan Q. Discussion and practice of clinical pharmacist system construction and working mode. Chin J Clin Pharmacol 2014;23:337-42.

4 Zeng Y, Hesketh T. The effects of China's universal two-child policy. Lancet 2016;388:1930-8.

$5 \mathrm{Hu}$ L. Thinking about the construction of a risk precaution system for highrisk pregnant women under the two -child policy. Chin J Pract Gynecol Obstet 2017:33:52-4

6 Lawal AK, Rotter T, Kinsman L, et al. What is a clinical pathway? Refinement of an operational definition to identify clinical pathway studies for a Cochrane Systematic Review. BMC Med 2016:14-35.

7 Moltó-Puigmartí C, Vonk R, van Ommeren G, et al. A logic model for pharmaceutical care. J Health Serv Res Policy 2018;23:148-57.

8 Liu F, Zhang T, Zhang X, et al. Development of high-alert medication list based on expert consensus and healthcare workers investigation. Chin Pharm J 2018;53:1523-8.

9 Chinese Medical Association obstetrics and gynecology branch, Chinese Medical Association perinatal medicine branch pregnancy with diabetes collaboration. Guidelines for diagnosis and treatment of pregnancy with diabetes mellitus. Chin J Obstet Gynecol 2014;49:561-9.

10 The American College of Obstetricians and Gynecologists Practice Bulletin No.202: gestational hypertension and preeclampsia. Obstet Gynecol 2019;133:e1-25.

11 The American College of Obstetricians and Gynecologists Practice Bulletin No. 148: thyroid disease in pregnancy. Obstet Gynecol 2015;125:996-1005.

12 Pang $Y$, Wang M, Wang $X$, et al. Establishment and practice of pharmaceutical care process for pregnancy complicated with diabetes mellitus. Chin Hosp Pharm J 2018;38:769-73.

13 Wang M, Pang Y, Yang Z, et al. Exploration of pharmaceutical care process for pregnancy combined with hypothyroidism or hyperthyroidism. Chin Pharm J 2018;53:561-4.

14 National Health Commission of the People's Republic of China. Notice on printing and distributing some opinions on controlling unreasonable growth of medical expenses in public hospitals[G] 2015.

15 Swieczkowski D, Poniatowski P, Merks P, et al. The pharmaceutical care in asthma Polish and global perspective. Pneumonol Alergol Pol 2016;84:225-31.

16 Wei L, Yang X, Li J, et al. Effect of pharmaceutical care on medication adherence and hospital admission in patients with chronic obstructive pulmonary disease (COPD): a randomized controlled study. J Thorac Dis 2014;6:656-62.

17 Juanes A, Garin N, Mangues MA, et al. Impact of a pharmaceutical care programme for patients with chronic disease initiated at the emergency department on drug-related negative outcomes: a randomised controlled trial. Eur J Hosp Pharm 2018:25:274-80.

18 Shao $\mathrm{H}$, Chen $\mathrm{G}$, Zhu C, et al. Effect of pharmaceutical care on clinical outcomes of outpatients with type 2 diabetes mellitus. Patient Prefer Adherence 2017;11:897-903.

19 Liang GK. Influence of key monitoring drugs policy on the change of adjuvant drugs in sample area. Chin Pharm J 2018;53:1613-8. 